\title{
UTILIZAÇÃO DE PARÂMETROS MORFOANATÔMICOS NA ANÁLISE DA FITOTOXIDEZ DO FLÚOR EM FOLHAS DE Magnolia ovata (A. St.-Hil.) SPRENG. (MAGNOLIACEAE) ${ }^{1}$
}

\author{
Bruno Francisco Sant' Anna-Santos ${ }^{2}$, Reinaldo Duque-Brasil ${ }^{2}$, Aristéa Alves Azevedo², Alice de Souza \\ Silveira ${ }^{2}$, João Marcos de Araújo ${ }^{3}$, Rosane Aguiar ${ }^{2}$
}

\begin{abstract}
RESUMO - Com os objetivos de avaliar o grau de suscetibilidade e caracterizar as injúrias na morfoanatomia de folhas de Magnolia ovata, mudas foram submetidas à chuva simulada com flúor $\left(10 \mu \mathrm{g} \cdot \mathrm{ml}^{-1}\right.$ de $\left.\mathrm{F}^{-}\right)$por 10 dias consecutivos. No tratamento controle, utilizou-se apenas água deionizada. Folhas foram coletadas para quantificação de flúor na matéria seca e fixadas para análises em microscopia de luz e eletrônica de varredura. As folhas apicais apresentaram pequena porcentagem de necroses intervenais e marginais em uma ou ambas as faces e maior acúmulo de flúor, em relação ao controle, quando comparadas com as folhas da porção basal. A análise micromorfológica das folhas aparentemente sadias indicou alterações nas paredes periclinais externas da epiderme e formação de concavidades, além de cristas estomáticas danificadas, erosão de ceras epicuticulares e presença de esporos e hifas de fungos. A caracterização estrutural das injúrias evidenciou retração de protoplasto das células epidérmicas, colapso das células do mesofilo e da epiderme e acúmulo de compostos fenólicos em células das regiões necrosadas. As alterações micromorfológicas das folhas ocorreram antes que sintomas fossem observados, o que comprova a importância da micromorfologia na diagnose precoce da injúria. As plantas de M. ovata apresentaram poucos sintomas visuais em resposta ao flúor, entretanto as alterações morfoanatômicas indicam que essa espécie possui potencial para ser utilizada como bioindicadora.
\end{abstract}

Palavras-chave: Flúor, anatomia foliar e Magnolia ovata.

\section{USE OF MORPHOANATOMIC PARAMETERS IN THE ANALYSIS OF FLUORIDE TOXICITY IN LEAVES OF Magnolia ovata (A. St.-Hil.) SPRENG. (MAGNOLIACEAE)}

\begin{abstract}
This work aimed to evaluate the degree of susceptibility and characterize the injuries caused by fluoride in the morphoanatomy of Magnolia ovata. Seedlings were subjected to fluoride simulated rain (10 $\mathrm{\mu g} . \mathrm{ml}^{-1}$ of $\left.\mathrm{F}^{-}\right)$during 10 consecutive days. In the control treatment, only deionized water was used. Leaves were collected for quantification of fluoride in the dry weight and fixed for light and scanning electron microscopy analyses. The apical leaves presented a small percentage of interveinal and margin necrosis in one or both leaf surfaces and greater fluoride accumulation, in relation to the control, than the basal portion leaves. Micromorphological analyses indicated that the areas apparently healthy of epidermis presented alterations in the external periclinal walls and formation of concave shapes, beyond damaged stomatic ledge, erosion of epicuticular waxes and presence of spores and fungal hyphae. The structural characterization of the injuries showed retraction of the protoplast of the epidermal cells, collapse of the mesophyll and epidermal cells and accumulation of phenolic compounds in cells of the necrotic regions. The micromorphological variations occurred before leaf symptoms, confirming the importance of micromorphology in early diagnosis of the injury. Plants of M. ovata presented few visible symptoms in response to fluoride; however, morphoanatomic responses suggest that this species possesses potential features to be used as a bioindicator.
\end{abstract}

Keywords: Fluoride, leaf anatomy and Magnolia ovata.

\footnotetext{
${ }^{1}$ Recebido em 20.10.2006 e aceito para publicação em 29.03.2007

${ }^{2}$ Departamento de Biologia Vegetal da Universidade Federal de Viçosa (UFV), 36570-000 Viçosa,MG, Brasil.

${ }^{3}$ Departamento de Biologia Geral da UFV.
} 


\section{INTRODUÇÃO}

O flúor encontrado na atmosfera, principalmente sob a forma de ácido fluorídrico (HF), apresenta grande fitotoxicidade (SMITHe HODGE, 1979) e pode ser liberado na atmosfera durante a produção de alumínio, tijolos, vidros e aço (FORNASIERO, 2001). A concentração de flúor na precipitação atmosférica varia entre $1 \mathrm{e}$ $1000 \mu \mathrm{g} . \mathrm{L}^{-1}$, podendo atingir $10 \mathrm{mg} . \mathrm{L}^{-1} \mathrm{em}$ áreas industriais (ARNDT et al., 1995). No Brasil, apesar de serem poucos os dados sobre a concentração de flúor na atmosfera, siderúrgicas e usinas alimentadas a carvão estão incluídas entre as principais fontes de emissão (DOBBS, 1974).

No Brasil, a água da chuva é afetada pela emissão de poluentes em regiões metropolitanas, como as do Rio de Janeiro e São Paulo (KLUMPP et al., 1994; MELLO, 2001), sendo algumas zonas industriais, como a do Vale do Aço em Minas Gerais, definidas como áreas de preocupação ambiental (JORDÃO et al., 1996). Mesmo em países desenvolvidos, com grande redução na emissão de fluoretos, injúrias na vegetação causadas pelo flúor ainda são muito comuns, devido à sua grande fitotoxicidade, justificando a seleção de espécies vegetais bioindicadoras (WEINSTEIN e DAVISON, 2003).

Algumas espécies capazes de tolerar a presença de poluentes, denominadas biosensores, reagem discretamente aos efeitos da poluição, sem sintomas visuais, sendo, dessa forma, fundamental a detecção de alterações utilizando-se técnicas microscópicas (DE TEMMERMAN et al., 2004). Já as espécies muito sensíveis, ou bioindicadores, reagem visualmente à ação de poluentes (DE TEMMERMAN et al., 2004). Entretanto, análises micromorfológicas e anatômicas podem auxiliar o diagnóstico precoce da injúria, antes do surgimento de sintomas visíveis (SILVA et al., 2000; SANT'ANNA-SANTOS et al., 2006a).

A análise qualitativa dos parâmetros morfoanatômicos vem sendo utilizada na determinação da sensibilidade das espécies vegetais a poluentes atmosféricos (SILVA et al., 2000; FORNASIERO, 2001; SOUKUPOVÁ et al., 2001; CHAVES et al., 2002; FORNASIERO, 2003; SILVAetal., 2005a,b; SANT'ANNASANTOS et al., 2006b). Alterações na estrutura dos órgãos vegetais provocadas por agentes estressantes têm sido verificadas (GAO et al., 1988; BURROWS et al., 1992; PAPADAKIS et al., 2004; TUFFI SANTOS et al., 2005), evidenciado-se que as análises quantitativas auxiliam na identificação dos efeitos negativos da poluição atmosférica (SOUKUPOVÁ et al., 2001).
No Brasil estão sendo realizados estudos visando determinar a resposta e o grau de sensibilidade de plantas nativas aos poluentes atmosféricos, com o intuito de selecionar espécies como bioindicadoras da qualidade do ar (WEINSTEIN e HANSEN, 1988; ARNDT et al., 1995; SILVA et al., 2000; DOMINGOS et al., 2004).

Magnolia ovata, popularmente conhecida como baguaçu, alcança até $30 \mathrm{~m}$ de altura, e sua madeira é empregada na indústria de caixotaria pequena, além de apresentar características ornamentais que a recomendam para o paisagismo. Adaptada a terrenos brejosos, cresce normalmente em solo inundado, razão por que é indicada para reflorestamentos mistos destinados à recomposição da vegetação em áreas ciliares degradadas (LOBO e JOLY, 1995; LORENZI, 2002). Estudos que avaliem a suscetibilidade de $M$. ovata a poluentes se justificam em face da ocorrência dessa espécie em florestas do Sudeste brasileiro, em áreas sujeitas à poluição atmosférica (MELLO e ALMEIDA, 2004).

A caracterização de sintomas ocasionados por fatores estressantes, de natureza biótica e, ou, abiótica, é, em geral, negligenciada em vários trabalhos de fisiologia, o que tem limitado a utilização dos sintomas visíveis de injúria para diagnóstico do fator de estresse (VOLLENWEIDER et al., 2003; VOLLENWEIDER e GÜNTHARDT-GOERG, 2005). Objetivou-se, neste estudo, caracterizar o efeito do flúor em folhas de plantas de M. ovata, por meio de parâmetros morfológicos e de sua correlação com as alterações anatômicas, contribuindo com informações sobre a sensibilidade da espécie.

\section{MATERIAL E MÉTODOS}

\subsection{Espécie e condições de cultivo}

Foram utilizadas mudas de Magnolia ovata St. Hill (Magnoliaceae), com cerca de $23 \mathrm{~cm}$ de altura e seis meses de idade, fornecidas pelo Viveiro do Instituto Estadual de Florestas (VIEF). As plantas foram cultivadas em substrato utilizado no VIEF (Tabela 1). Todas as plantas receberam solução nutritiva de Hoagland a $1 / 4$ de força (HOAGLAND e ARNON, 1950) a cada cinco dias, seguindo a metodologia proposta por Silva et al. (2005b). 
Tabela 1 - Resultados da análise química do solo utilizado como substrato nos vasos Table 1 - Chemical analysis of the soil used as pot substrate

\begin{tabular}{ccccccccccc}
\hline $\begin{array}{c}\mathrm{pH} \\
\mathrm{H}_{2} \mathrm{O}\end{array}$ & $\mathrm{P}$ & $\begin{array}{c}\mathrm{K} \\
\mathrm{mg} / \mathrm{dm}^{3}\end{array}$ & $\mathrm{Na}$ & $\mathrm{Ca}^{2+}$ & $\mathrm{Mg}^{2+}$ & $\mathrm{Al}^{3+}$ & $\begin{array}{c}\mathrm{H}+\mathrm{Al} \\
\mathrm{cmol}_{\mathrm{c}} / \mathrm{dm}^{3}\end{array}$ & $\mathrm{SB}$ & $(\mathrm{t})$ & $(\mathrm{T})$ \\
\hline 4,54 & 0,9 & 21 & - & 0,31 & 0,2 & 0,2 & 2,3 & 0,56 & 0,76 & 2,86 \\
\hline $\mathrm{V}$ & $\mathrm{m}$ & $\mathrm{ISNa}$ & $\begin{array}{c}\mathrm{MO} \\
\mathrm{dag} / \mathrm{kg}\end{array}$ & $\begin{array}{c}\mathrm{P}-\mathrm{rem} \\
\mathrm{mg} / \mathrm{L}\end{array}$ & $\mathrm{Zn}$ & $\mathrm{Fe}$ & $\mathrm{Mn}$ & $\mathrm{Cu}$ & $\mathrm{B}$ & $\mathrm{S}$ \\
\hline 19,6 & 26,3 & - & 1,14 & 10,6 & - & 27 & 9,5 & 2,9 & 4,55 & 18,7 \\
\hline
\end{tabular}

Abreviaturas: SB (Soma de bases trocáveis); CTC (t) (Capacidade de troca catiônica efetiva); CTC (T) (Capacidade de troca catiônica a $\mathrm{pH}=7,0$ ); V (Índice de saturação de bases); $\mathrm{m}$ (Índice de saturação de alumínio); ISNa (Índice de saturação de sódio); e MO (Matéria orgânica = C. Org $\times 1.724-$ Walkley-Black); P-rem (Fósforo remanescente)

Abbreviations: SB (Sum of exchangeableable bases); CTC $(t)$ (effective cation capacity exchangeable); CTC $(T)($ cation to capacity exchangeable pH 7.0); V(Index of base saturation); $m$ (Index of aluminum saturation); ISNa (Index of sodium saturation); MO (Organic matter = C.Org $\times 1.724-$ Walkley-Black); P-rem (Remain phosphorus)

O experimento foi realizado na Unidade de Crescimento de Plantas, da Universidade Federal de Viçosa, (UFV) em Viçosa, MG, localizada a $649 \mathrm{~m}$ de altitude, $20^{\circ} 45^{\prime} 20^{\prime \prime}$ de latitude sul e $42^{\circ} 52^{\prime}$ '40' de longitude oeste. O clima da região é tropical de altitude, tipo Cwb, com verões brandos de temperatura média do mês mais quente inferior a $22^{\circ} \mathrm{C}$ (KÖEPPEN, 1948).

\subsection{Tratamentos}

O experimento de simulação seguiu metodologia proposta por Silva et al. (2000). As plantas de M. ovata foram expostas por 10 dias consecutivos e períodos de $20 \mathrm{~min} /$ dia à chuva com flúor e água (controle), totalizando $18,7 \mathrm{~mm} /$ dia de precipitação em uma câmara de simulação, com sistema de "spray", adaptada do modelo proposto por Evans et al. (1977). O tratamento com flúor foi preparado adicionando-se fluoreto de potássio em água deionizada $\left(10 \mathrm{mg} . \mathrm{L}^{-1}\right)$ e o controle - somente água deionizada $(\mathrm{pH}=6,0)$. Antes e após os tratamentos, as plantas ficaram expostas sob um painel luminoso composto por oito lâmpadas incandescentes de mercúrio (E-27, 220-230 volts, 250 watts) por $15 \mathrm{~min}$ sob densidade de fluxo radiante de $95 \mathrm{~W} . \mathrm{m}^{-2}$. As plantas de M. ovata foram mantidas em condições ambientais (Figura 1) durante o experimento (28 de julho a 6 de agosto de 2004). Após a chuva, todas as folhas foram fotografadas, com o objetivo de documentar as modificações visíveis ocasionadas pelo poluente.

\subsection{Determinação do teor de flúor}

Para a quantificação do conteúdo de flúor foram coletadas folhas da região apical $\left(1^{\circ}\right.$ ao $3^{\circ}$ nó a partir da gema apical) e basal ( $4^{\circ}$ ao $6^{\circ}$ nó) das plantas de M. ovata, 24 h depois da aplicação da última chuva. As amostras foram previamente secadas em estufa, a $70^{\circ} \mathrm{C}$, e reduzidas, em moinho do tipo Wiley, a partículas com dimensões inferiores a $1 \mathrm{~mm}$. Posteriormente, alíquotas de $0,5 \mathrm{~g}$, de cada repetição, foram submetidas à extração com ácido perclórico 0,1 M(GARCIA-CIUDAD et al., 1985), utilizando-se o ajustador de força iônica (LARSEN e WIDDOWSON, 1971), para determinação potenciométrica do teor de flúor, com eletrodo específico. O delineamento experimental foi o inteiramente casualizado com cinco repetições por tratamento.

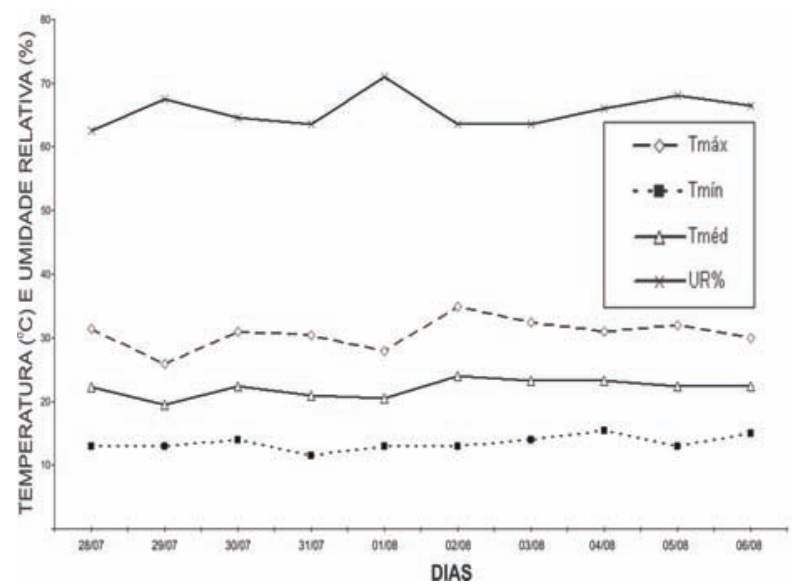

Figura 1 - Temperatura máxima (Tmáx), mínima (Tmin) e média (Tméd) e umidade relativa (UR\%) em casa de vegetação, 28 de julho a 06 de agosto de 2004.

Figure 1-Maximum temperature (Tmáx), minimum (Tmin), mean (Tméd) and relative humidity $(U R \%)$ in greenhouse, July 28 to August 06, 2004.

R. Árvore, Viçosa-MG, v.31, n.4, p.761-771, 2007 


\subsection{Análise micromorfológica}

Folhas jovens ( $2^{\circ}$ nó) e expandidas ( $5^{\circ}$ nó) de cinco plantas foram coletadas $24 \mathrm{~h}$ após o término das simulações, fixadas em solução de glutaraldeído (2,5\%), paraformaldeído (4\%) em tampão cacodilato de sódio pH 7,2 e acrescido de cloreto de cálcio $5 \mathrm{mM}$ (KARNOVSKY, 1965). As amostras de folhas foram pós-fixadas em tetróxido de ósmio $1 \%$, desidratadas em série etílica, e a secagem ao ponto crítico em equipamento apropriado (modelo CPD 020, Bal-Tec, Balzers). Em metalizador (modelo FDU010, Bal-Tec, Balzers), a superfície das folhas foi coberta com ouro e documentada em microscópio eletrônico de varredura com câmera digital (modelo JSMT200, Jeol Co.), do Núcleo de Microscopia e Microanálise da UFV.

\subsection{Análise micromorfométrica e estrutural}

Para a análise micromorfométrica, cinco lâminas foliares expandidas $\left(5^{\circ}\right.$ nó) foram fixadas em FAA (preparado com etanol 70\%), desidratadas em série etílica e incluídas em metacrilato (Historesina, Leica Instruments). Para montagem de lâminas permanentes, cortes transversais das folhas, com $4 \mu \mathrm{m}$ de espessura, obtidos em micrótomo rotativo de avanço automático (modelo RM2155, Leica Microsystems Inc.), foram corados com azul de toluidina pH 4,0 (O`BRIEN e McCULLY, 1981) e montados em Permount. As espessuras do limbo e do mesofilo e a altura das células epidérmicas foram mensuradas nas folhas de $M$. ovata, utilizandose o software Image-Pro Plus 4.1; foram realizadas 45 medidas/repetição/parâmetro, totalizando 225 registros. Na comparação estatística das médias dos tratamentos, utilizaram-se a análise de variância e o teste de Tukey a $5 \%$ de probabilidade $(\mathrm{p} \leq 0,05)$.

Para a caracterização estrutural das regiões das folhas jovens ( $2^{\circ}$ nó) compreendendo a nervura mediana, margem e porção intervenal, amostras foram fixadas em FAA (preparado com etanol 70\%), desidratadas em série etílica/butílica e incluídas em parafina histológica. Secções transversais das folhas, com $10 \mu \mathrm{m}$ de espessura obtidos em micrótomo rotativo (modelo Spencer 820, American Optical Corporation, New York, USA), foram corados com fucsina básica $0,1 \%$ durante 60 min e azul de astra $1 \%$ por 3 min e montados em Permount. As observações e documentação fotográfica foram realizadas em fotomicroscópio (modelo Olympus AX70TRF, Olympus Optical) com sistema U-Photo.

\section{RESULTADOS E DISCUSSÃO}

A morfologia das folhas de Magnolia ovata (Figura 2) apresentou poucos danos visíveis ( $0,8 \%$ da área) em resposta ao tratamento com flúor com pequenas manchas necróticas intervenais e marginais em uma ou ambas as faces (Figura 2B-E), observada após o quinto dia de tratamento somente em folhas da porção apical de uma planta das repetições.

Os sintomas visíveis nas folhas têm sido empregados no monitoramento do efeito dos estresses abióticos e bióticos(VOLLENWEIDEReGÜNTHARDT-GOERG2005), com os primeiros sintomas de cloroses na região marginal e intervenal e necroses ocorrendo em teores de flúor elevados (WEINSTEIN e DAVISON, 2003). Os sintomas causados pelo flúor em folhas de $M$. ovata foram similares aos observados por Silva et al. (2000) em Gallesia gorazema, Genipa americana, Joannesia princeps, Peltophorum dubium e Spondias dulcis.

As folhas jovens de Pinus contorta são mais sensíveis ao flúor (WEINSTEIN e DAVISON, 2003), conforme observado nas de M. ovata, com as injúrias formadas somente em folhas em desenvolvimento. Entretanto, em folhas de plantas de Hypericum perforatum submetidas pelo sistema radicular ao flúor, as injúrias iniciaram-se em folhas totalmente expandidas, enquanto as em desenvolvimento não apresentaram sintomas visíveis (FORNASIERO, 2001). Silva et al. (2000) submeteram plantas de espécies arbóreas nativas à chuva simulada com flúor, observando maior intensidade de sintomas em folhas jovens de Joannesia princeps e Peltophorum dubium e em folhas desenvolvidas de Spondias dulcis e Gallesia gorazema.

Apesar de plantas de $M$. ovata não apresentarem danos visuais expressivos, houve acúmulo de flúor na matéria seca das folhas da sua região apical e basal quando expostas ao poluente de 28 e 7,6\% maior do que no controle, respectivamente (Tabela 2). O conteúdo de flúor nas folhas das plantas situa-se entre 2-20 $\mu \mathrm{g} . \mathrm{g}^{-1}$ da sua matéria seca (POSTHUMUS, 1983; KLUMPP et al., 1994), conforme verificado no tratamento controle. Em plantas expostas ao flúor, a quantidade acumulada e o grau de injúria nos tecidos foliares variam com a espécie, idade da folha, características do solo e ritmo de crescimento das plantas (SILVA et al., 2000).

Em microscopia eletrônica de varredura, observouse que as folhas de M. ovata são desprovidas de tricomas (Figuras 3A-C). No tratamento com flúor, ocorreram alterações na epiderme como a formação de concavidades 
em certas regiões (Figuras 3B-E), danos nas cristas estomáticas (Figura 3F) e erosão de ceras epicuticulares (Figura 4C), além da colonização da superfície foliar por fungos (Figuras 4D-E) e aglomeração de esporos (Figura 4F). Nas folhas jovens e expandidas sem sintomas, o flúor causou danos severos na superfície epidérmica, evidenciando-se que as alterações micromorfológicas antecedem os danos visíveis e estruturais também relatados em outras espécies arbóreas e herbáceas expostas ao flúor e à chuva ácida (CHAVES et al., 2002; SILVA et al., 2005a,b; SANT' ANNA-SANTOS et al., 2006b). Essas alterações podem estar relacionadas com a possibilidade de atuação do flúor na desestruturação da cutícula e das ceras epicuticulares, facilitando a sua entrada na epiderme e permitindo a invasão por patógenos (HEREDIA et al., 1998).

O mesofilo e a epiderme representam, respectivamente, 83,2 e $16,8 \%$ da espessura total da folha de plantas de $M$. ovata, sem diferença significativa em relação as submetidas ao flúor (Tabela 3). A espécie apresenta folhas dorsiventrais e hipoestomáticas, epiderme unisseriada e idioblastos localizados entre o parênquima paliçádico e o lacunoso (Figura 5A). O sistema vascular apresenta feixes vasculares colaterais com fibras associadas (Figura 5B); na nervura mediana, os feixes se dispõem em círculo, delimitando uma medula parenquimática, com destaque para as fibras de parede lignificada externas ao floema (Figura 5B). Na margem das folhas ocorrem idioblastos com paredes lignificadas (Figuras 5C-D), que se assemelham aos idioblastos traqueoidais descritos por Tucker (1964), para espécies do gênero Magnolia.

Tabela 2 - Valores médios da concentração de flúor ( $\mu \mathrm{g} \cdot \mathrm{g}^{-1} \mathrm{de}$ matéria seca), na lâmina foliar de Magnolia ovata, 24 horas após a última chuva com fluoreto de potássio $\left(10 \mu \mathrm{g} \cdot \mathrm{ml}^{-1} \mathrm{de} \mathrm{F}^{-}\right)$

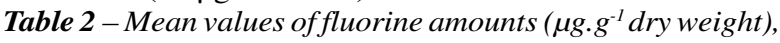
on leafblade of Magnolia ovata, 24 hours after the last rain with potassium fluoride (10 $\left.\mu \mathrm{g} . \mathrm{ml}^{-1} \mathrm{de} \mathrm{F}^{-}\right)$

\begin{tabular}{ccc}
\hline $\begin{array}{c}\text { Porção da folhagem } \\
\text { da planta }\end{array}$ & Controle & Flúor \\
\hline Apical & $21,11 \mathrm{~b} \pm 0,38$ & $27,05 \mathrm{a} \pm 1,25$ \\
Basal & $20,32 \mathrm{~b} \pm 0,30$ & $21,86 \mathrm{a} \pm 0,32$ \\
\hline
\end{tabular}

Médias seguidas por letras iguais na horizontal não diferem entre si quando comparadas pelo teste de Tukey a $5 \%$.

Means in the rows followed by the same letter are not significantly different by Tukey's test at $5 \%$.
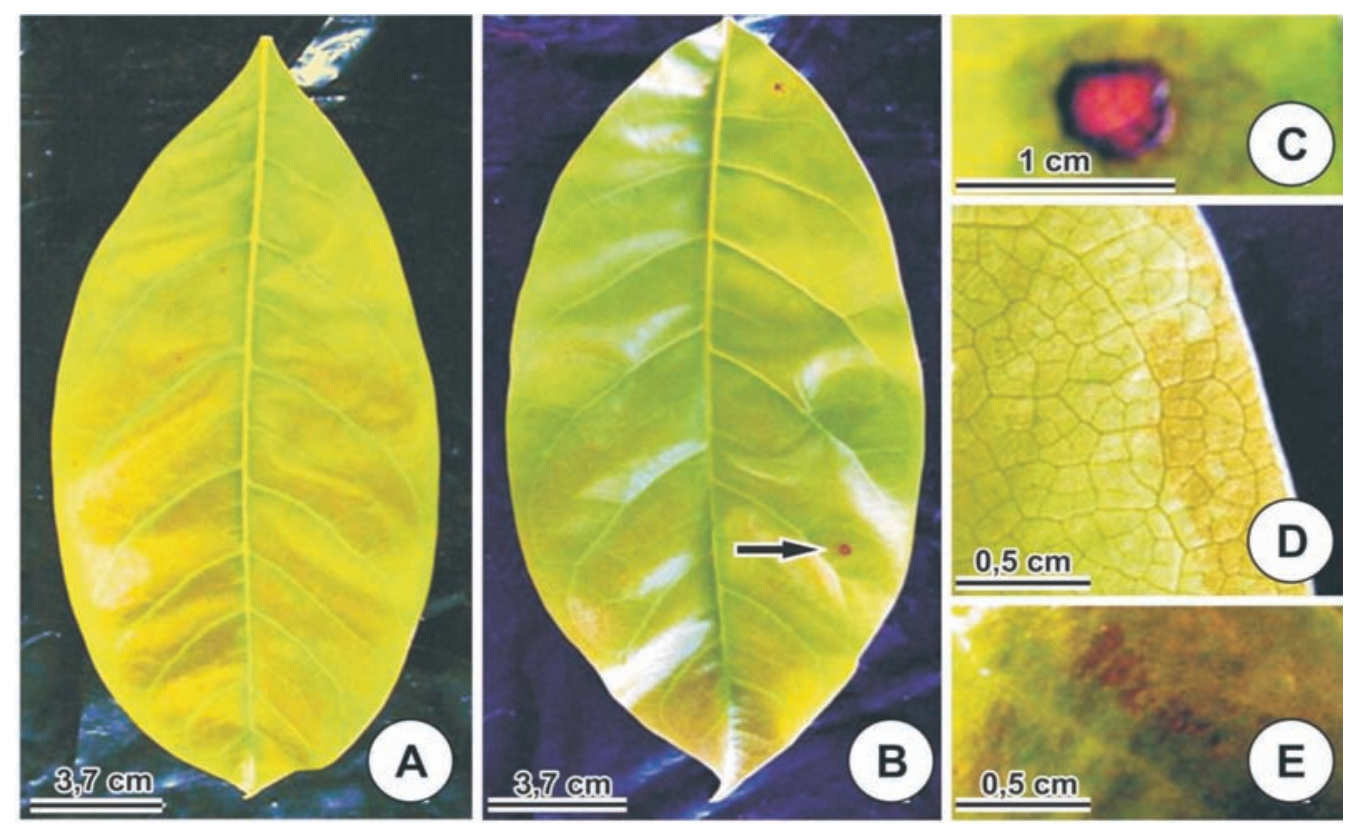

Figura 2 - Folhas de mudas de Magnolia ovata. A: Tratamento controle; B-E: Efeito do flúor; B: Mancha necrótica na região intermediária; C: Detalhe da necrose; D: Necrose marginal na face abaxial; e E: Manchas necróticas na face adaxial.

Figure 2 - Leaves of Magnolia ovata seedlings. A. Control treatment. B-E. Effects of fluoride. B. Interveinal necrotic spot. C. Detail of the necrosis. D. Marginal necrosis on the abaxial epidermis. E. Necrotic spots on the adaxial epidermis. 

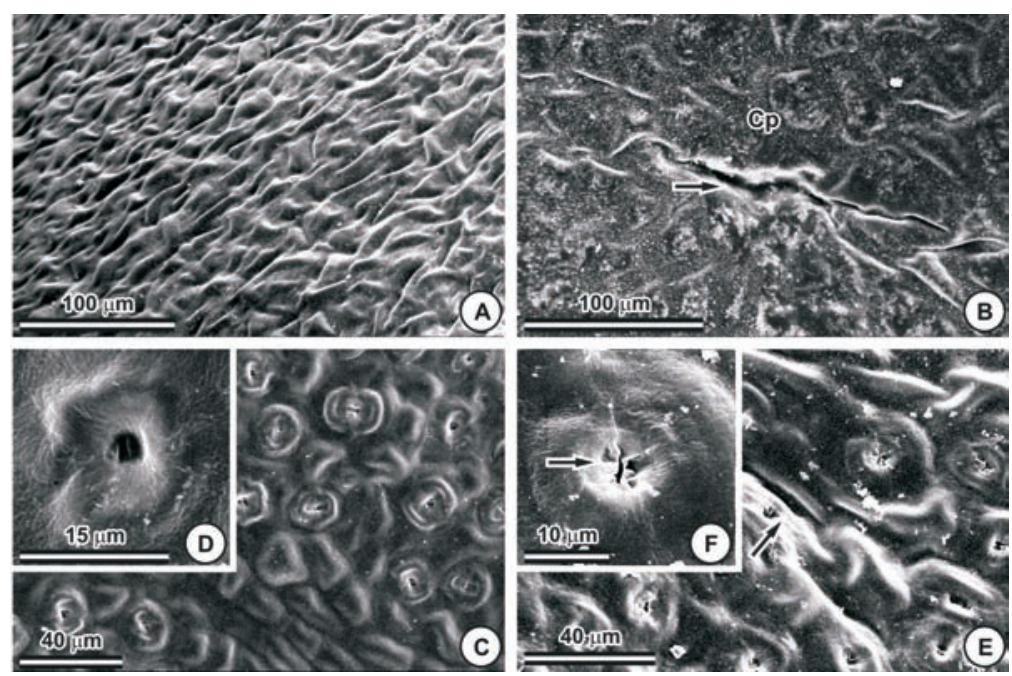

Figura 3 - Superfície da lâmina foliar em expansão de Magnolia ovata (micrografias eletrônicas de varredura). A, C e D: Tratamento controle; B, E e F: Efeitos do flúor; A: Face adaxial; B: Formação de concavidades (seta) próximos a células com paredes externas achatadas $(\mathrm{Cp})$; C: Face abaxial no tratamento controle; D: Estômato; E: Depressões na superfície (seta) próxima a estômatos danificados; e F: Crista estomática danificada (seta).

Figure 3 - Expanding leaf blade surface of Magnolia ovata (scanning electron micrographs). A, D and C. Control treatment. $B, E$ and F. Fluoride effects. A. Adaxial epidermis. B. Depressions (arrows) near to cells with flattened outer walls $(C p)$. C. Abaxial epidermis of control treatment. D. Stomata. E. Surface depressions (arrow) and damaged stomata. F. Ruptured stomata outer ledge (arrow).
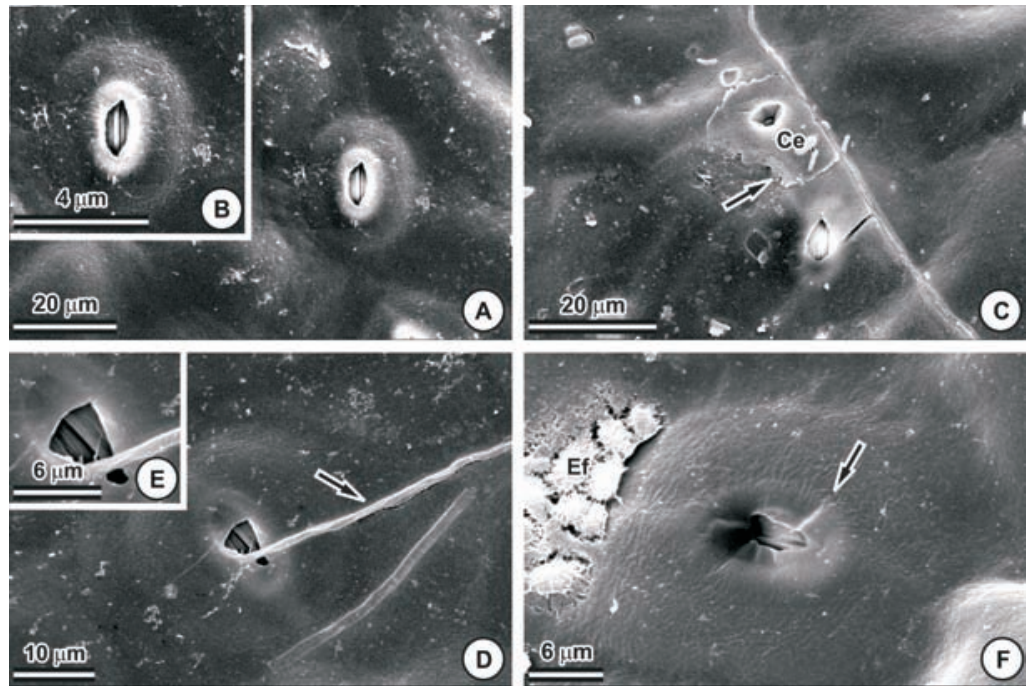

Figura 4 - Superfície da lâmina foliar expandida de Magnolia ovata (micrografias eletrônicas de varredura). A e B: Tratamento controle; C-E: Efeitos do flúor; A: Face abaxial; B: Estômato; C: A seta indica a transição entre a região com e sem cera epicuticular (Ce); D: Hifa fúngica na superfície da folha; E: Hifa fúngica no estômato; e F: Crista estomática danificada (seta) e aglomerado de esporos fúngicos (Ef).

Figure 4 - Expanded leaf blade surface of Magnolia ovata (scanning electron micrographs). A and B. Control treatment. C-E. Fluoride effects. A. Abaxial epidermis. B. Stomata. C. Arrow indicates the transition of region with and without epicuticular wax $(\mathrm{Ce})$. D. Fungi hyphae on the leaf surface. E. Fungi hyphae in stomata. F. Ruptured outer ledge stomata (arrow) and agglomerate of fungi spores (Ef).

R. Árvore, Viçosa-MG, v.31, n.4, p.761-771, 2007 
Tabela 3 - Espessura da lâmina foliar e do mesofilo e altura das células epidérmicas em plantas de Magnolia ovata submetidas à chuva simulada com flúor $(10$ $\mu \mathrm{g} \cdot \mathrm{ml}^{-1} \mathrm{de} \mathrm{F}^{-}$), em comparação com o tratamento controle

Table 3 - Leaf and mesophyll thickness and epidermal cell height of Magnolia ovata subjected to simulated fluoride rain (10 $\left.\mu \mathrm{g} . \mathrm{ml}^{-1} \mathrm{de} \mathrm{F}^{-}\right)$in comparison with control treatment

\begin{tabular}{lcr}
\hline Espessura/Altura $(\mu \mathrm{m})$ & \multicolumn{1}{c}{ Controle } & \multicolumn{1}{c}{ Flúor } \\
\hline Folha & $203,16 \mathrm{a} \pm 5,34$ & $204,09 \mathrm{a} \pm 9,49$ \\
Epiderme (face adaxial) & $18,75 \mathrm{a} \pm 0,87$ & $19,10 \mathrm{a} \pm 1,33$ \\
Mesofilo & $169,09 \mathrm{a} \pm 6,02$ & $170,52 \mathrm{a} \pm 8,57$ \\
Epiderme (face abaxial) & $15,32 \mathrm{a} \pm 0,96$ & $14,48 \mathrm{a} \pm 0,84$ \\
\hline
\end{tabular}

Médias si quando comparadas pelo teste de Tukey a $5 \%$.

Means of the same line marked with the same letter are not significantly different by Tukey's test at 5\%.

A epiderme na região da mancha necrótica tem intensa coloração avermelhada da fucsina e distorções na forma das células (Figura 5F), não observada no controle (Figura 5E). Nas manchas necróticas intervenais, observou-se a condensação do conteúdo celular da epiderme (Figura 6A), o colapso de células da face abaxial da epiderme e o acúmulo de compostos escuros no parênquima lacunoso (Figura 6B). Em outras áreas necróticas, as células epidérmicas apresentam aspecto plasmolisado e conteúdo escuro, e os elementos xilemáticos encontram-se colapsados (Figura 6C). Em áreas aparentemente sadias, as células epidérmicas apresentam retração do protoplasto (Figura 6A), indicando que esse sintoma antecede o colapso celular e o subseqüente acúmulo de compostos escuros, verificado em áreas necrosadas (Figura 6C). Na região da margem da folha também observaram-se condensação do conteúdo celular e diminuição do volume de algumas células epidérmicas (Figura 6E), em contraste com o tratamento controle (Figura 6D).
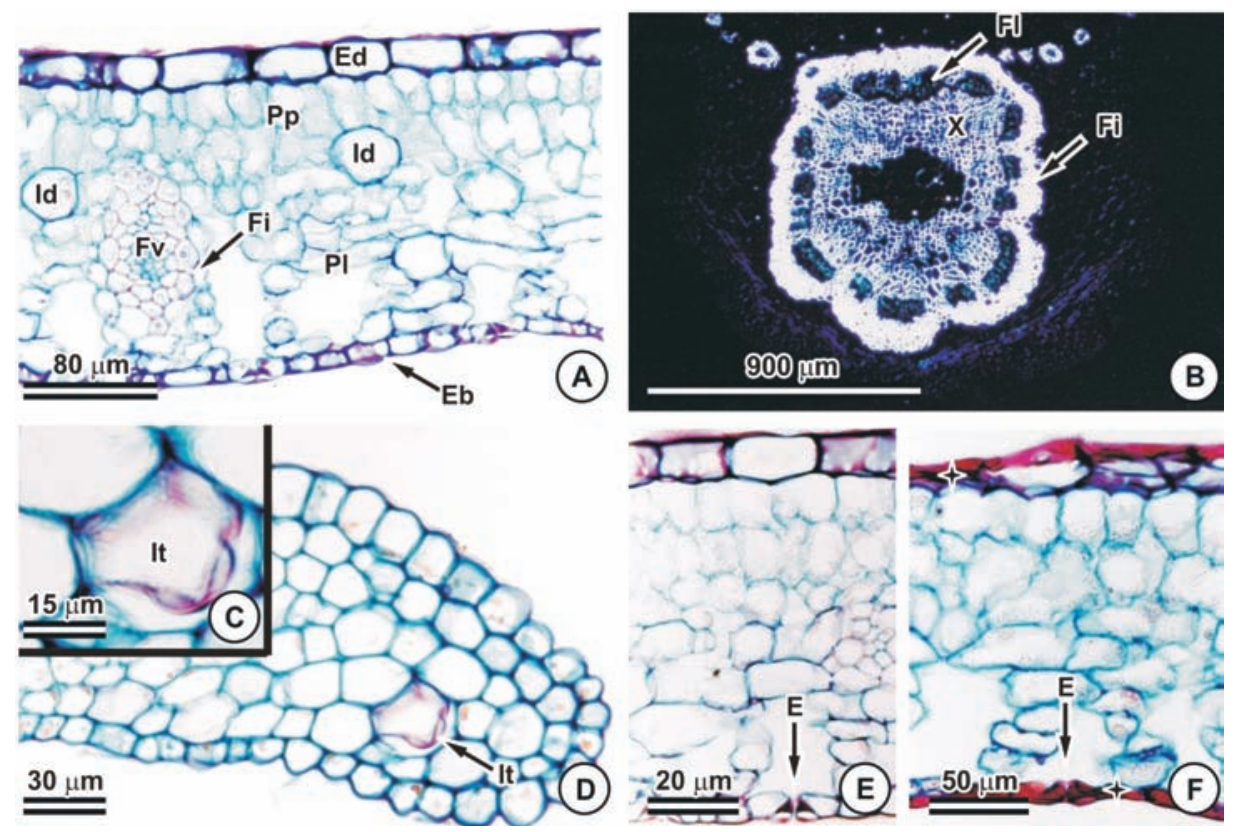

Figura 5 - Estrutura foliar de Magnolia ovata (secções transversais em microscopia de luz). A-E: Tratamento controle; F: Efeitos do flúor; A: Região entre a margem e a nervura mediana; B: Nervura mediana submetida à luz polarizada; C: Idioblasto traqueoidal; D: Margem da folha; E: Folha hipoestomática; e F: Células epidérmicas com forma alterada e intensamente coradas pela fucsina. Abreviaturas: E (estômato); Eb (face abaxial da epiderme); Ed (face adaxial da epiderme); Fi (fibras); Fl (floema); Fv (feixe vascular); Id (idioblasto); It (idioblasto traqueoidal); Pl (parênquima lacunoso); e Pp (Parênquima paliçádico).

Figure 5 - Leaf blade structure of Magnolia ovata (cross-section light micrographs). A-E. Control treatment. F. Fluoride effects. A. Leaf middle region. B. Midrib under polarized light. C. Tracheoidal idioblasts. D. Leaf margin. E. Hypostomatic leave. F. Epidermal cells shape altered and strongly stained by fuchsine. Abbreviations: E (Stomata); Eb (abaxial epidermis); Ed (adaxial epidermis); Fi (fibers); Fl (phloem); Fv (vascular bundle); Id (idioblast); It (tracheoidal idioblast); Pl (spongy parenchyma); $P$ p (palisade parenchyma). 

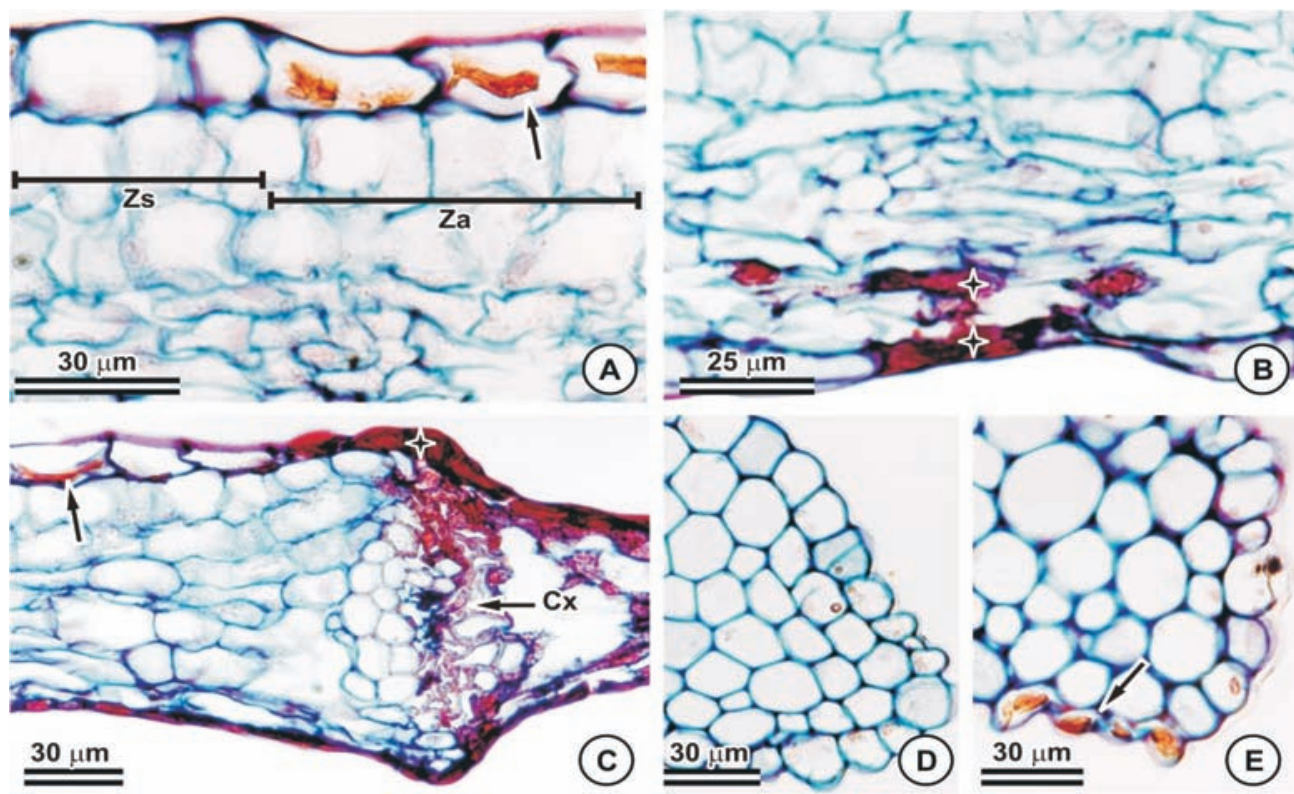

Figura 6 - Estrutura foliar de Magnolia ovata (secções transversais em microscopia de luz). A, B, C e E: Efeitos do flúor; D: Tratamento controle; A: Retração do protoplasto (seta) na interface entre a zona afetada (Za) e sadia (Zs); B: Necrose iniciada a partir da face abaxial da epiderme e acúmulo de compostos fenólicos (estrelas); C: Colapso dos elementos xilemáticos $(\mathrm{Cx})$ e retração do protoplasto nas células epidérmicas (seta); D: Células epidérmicas na margem da folha no tratamento controle; e E: Retração nas células epidérmicas da margem da folha (seta).

Figure 6 - Leaf blade structure of Magnolia ovata (cross-section light micrographs). A, B, C and E. Fluoride effects. D. Control treatment. A. Protoplasm retraction (arrow) in the interface of affected and healthy region. B. Necrosis start from abaxial epidermis and phenolic compounds accumulation (stars). C. Collapsed xylem elements $(C x)$ and protoplasm retraction of epidermal cells (arrow). D. Epidermal cell on the leaf margin in the control treatment. E. Retraction of epidermal cells of leaf margin (arrow).

O estudo anatômico das regiões necrosadas demonstrou que as alterações observadas são similares às encontradas em espécies visualmente mais sensíveis, porém submetidas a concentrações mais elevadas de flúor(SILVAet al., 2000; CHAVES et al., 2002). Os conteúdos escuros intensamente corados pela fucsina, em áreas necróticas das folhas de $M$. ovata, são atribuídos por Silva et al. (2000) e Chaves et al. (2002), em plantas expostas ao poluente, ao acúmulo de compostos fenólicos como comprovado, por meio de reações histoquímicas específicas, em espécies do gênero Picea (SOUKUPOVÁ et al., 2001). O acúmulo de fenóis tem sido interpretado como um mecanismo de defesa das plantas, ativado por fatores bióticos e abióticos que induzem ao estresse (VAUGHN e DUKE, 1984).

Os sintomas visíveis das folhas da região apical das plantas de M. ovata indicam maior suscetibilidade, provavelmente por acumularem mais flúor. Em algumas espécies vegetais existe relação entre o maior grau de injúria e as taxas elevadas de acúmulo de flúor (KLUMPPet al., 1995; SILVA et al., 2000; FORNASIERO, 2001). Alterações severas foram observadas na superfície das folhas aparentemente sadias, revelando que os sintomas externos são restritivos na avaliação do efeito de substâncias fitotóxicas e para a diagnose de injúrias, como observado em clones de Eucalyptus submetidos à ação do herbicida glyphosate (TUFFI SANTOS et al., 2007).

Os resultados obtidos permitem afirmar que as plantas de $M$. ovata apresentaram alterações significativas na micromorfologia foliar em resposta ao flúor, mesmo nas folhas sem injúrias visíveis. Pela extensão dos sintomas externos, conclui-se que as plantas da espécie foram levemente injuriadas, mostrando manchas cloróticas e necróticas esparsas. As respostas morfoanatômicas nas folhas, características dos efeitos do flúor, indicam que essa espécie possui potencial como bioindicadora de ambientes impactados pelo flúor. 


\section{AGRADECIMENTOS}

À FAPEMIG (CRA910/02), pelo aporte financeiro, ao Instituto Estadual de Florestas (IEF), pelo fornecimento das plantas; e à Prof ${ }^{a}$ Luzimar Campos da Silva, pelas sugestões na redação do texto deste artigo.

\section{REFERÊNCIAS}

ARNDT, U.; FLORES, F.; WEINSTEIN, L. Efeitos do flúor sobre as plantas: diagnose de danos na vegetação do Brasil. Porto Alegre: Universidade Federal do Rio Grande do Sul, 1995. 155p.

BURROWS, G. E.; BOAG, T. S.; STEWART, W. P. Changes in leaf, stem, and root anatomy of Chrysanthemum cv. Lillian Hoek following paclobutrazol application. Journal of Plant Growth Regulation, v.11, p.189-194, 1992.

CHAVES A.L.F. et al. Ação do flúor dissolvido em chuva simulada sobre a estrutura foliar de Panicum maximum Jacq. (colonião) e Chloris gayana Kunth. (capim-rhodes) - Poaceae. Acta Botânica Brasílica, v.16, p.395-406, 2002.

DE TEMMERMAN, L. et al. Biomonitoring of air pollutants with plants - considerations for the future. In: KLUMPP, A.; ANSEL, W.; KLUMPP, G. (Eds) Urban air pollution, bioindication and environmental awareness. Göttingen: Cuvillier Verlag, 2004. 392p.

DOBBS, C. G. Fluoride and the environment. Fluoride, v.7, p.123-135, 1974.

DOMINGOS, M. et al. Reactions of Caesalpinia echinata Lam., a Brazilian tree species, to urban air pollution stress. In: KLUMPP, A.; ANSEL,

W.; KLUMPP, G. (Eds). Urban air pollution, bioindication and environmental awareness. Göttingen: Cuvillier Verlag, 2004. 392p.

EVANS, L. S.; GMUR, N. F.; COSTA, F. Leaf surface and histological perturbations of leaves of Phaseolus vulgaris and Helianthus annuus after exposure to simulated acid rain. American Journal of Botany, v.64, p.903-913, 1977.
FORNASIERO, R. B. Phytotoxic effects of fluorides. Plant Science, v.161, p.979-985, 2001.

FORNASIERO, R. B. Fluorides effects on Hypericum perforatum plants: first field observations. Plant Science, v. 165 , p.507-513, 2003.

GAO, J.; HOFSTRA, G.; FLETCHER, R. A. Anatomical changes induced by triazoles in wheat seedlings. Canadian Journal of Botany, v.66, p.1178-1185, 1988.

GARCIA-CIUDAD, A.; GARCIA-CAIADO, E. L.; PONTONSAN EMETERIO, C.

Determination of fluoride in plant samples by a potentiometric method and near-infrared reflectance spectroscopy.

Communications in Soil Science and Plant Analysis, v.16, p.1107-1122, 1985.

HEREDIA, A. et al.. La cuticula vegetal: estructura y funciones. Ecología, v.12, p.293-305, 1998.

HOAGLAND, D. R.; ARNON, D. I. The waterculture method for growing plants without soil. Berkeley: California Agricultural Experiment Station, 1950.

JORDÃO, C. P. et al.Heavy metal dispersion from industrial wastes in the Vale do Aço, Minas Gerais, Brazil. Environmental Technology, v.17, p.489-500, 1996.

KARNOVSKY, M. J. A formaldehydeglutaraldehyde fixative of high osmolarity for use in electron microscopy. Journal of Cell Biology, v.27, p.137-138, 1965.

KLUMPP, A.; KLUMPP, G.; DOMINGOS, M. Plants as bioindicators of air pollution at the Serra do Mar near the industrial complex of Cubatão, Brazil. Environmental Pollution, v.85, p.109-116, 1994.

KLUMPP, A. et al. Hemerocallis as bioindicator of fluoride pollution in tropical countries.

Environmental Monitoring and Assesment, v.35, p.27-42, 1995.

R. Árvore, Viçosa-MG, v.31, n.4, p.761-771, 2007 
KÖEPPEN, W. Climatologia: com un estudio de los climas de la tierra. In: HENDRICHS PÉREZ, P. R. (Ed.). México, DF: Fondo de Cultura Econômica, 1948. p.152-182.

LARSEN, S.; WIDDOWSON, A. E. Soil fluorine. Journal of Soil Science, v.22, p.210-221, 1971.

LOBO, P. C.; JOLY, C. A. Mecanismos de tolerância à inundação de plantas de Talauma ovata St. Hil. (Magnoliaceae), uma espécie típica de matas de brejo. Revista Brasileira de Botânica, v.18, p.177-183, 1995.

LORENZI, H. Árvores brasileiras: manual de identificação e cultivo de plantas arbóreas nativas do Brasil. Nova Odessa: Instituto Plantarum: 2002. 368p.

MELLO, W. Z. Precipitation chemistry in the coast of the Metropolitan Region of Rio de Janeiro, Brazil. Environmental Pollution, v.114, p.235-242, 2001.

MELLO, W. Z.; ALMEIDA, M. D. Rainwater chemistry at the summit and southern flank of the Itatiaia massif, Southeastern Brazil. Environmental Pollution, v.129, p.63-68, 2004.

O'BRIEN, T. P.; McCULLY, M. E. The study of plant structure principles and select methods. Melbourne: Termarcaphi Pty, 1981. 45p.

PAPADAKIS, I. E. et al. Effects of B excess on some physiological and anatomical parameters of 'Navelina' orange plants grafted on two rootstocks. Environmental and Experimental Botany, v.51, p.247-257, 2004.

POSTHUMUS, A. C. Higher plants as indicators and accumulators of gaseous air pollution. Environmental Monitoring and Assesment, v.3, p.263-272, 1983.

SANT'ANNA-SANTOS, B. F. et al. Effects of simulated acid rain on leaf anatomy and micromorphology of Genipa americana L. (Rubiaceae). Brazilian Archives of Biology and Technology, v.49, p.313-321, 2006a.

SANT'ANNA-SANTOS, B. F. et al. Effects of simulated acid rain on the foliar micromorphology and anatomy of tree tropical species. Environmental and Experimental Botany, v.58, p.158-168, 2006b.

R. Árvore, Viçosa-MG, v.31, n.4, p.761-771, 2007
SILVA, L. C. et al. Flúor em chuva simulada: sintomatologia e efeitos sobre a estrutura foliar e o crescimento de plantas arbóreas. Revista Brasileira de Botânica, v.23, p.385-393, 2000.

SILVA, L. C. et al. Effects of simulated acid rain on the growth and anatomy of five Brazilian tree species and anatomy of the most sensitive species (Joannesia princeps). Australian Journal of Botany, v.53, p.789-796, 2005a.

SILVA, L. C. et al. Micromorphological and anatomical alterations caused by simulated acid rain in restinga plants: Eugenia uniflora and Clusia hilariana. Water, Air and Soil Pollution, v.168, p.129-143, 2005b.

SMITH, F. A.; HODGE, H. C. Airbone fluorides and man: Part I. CRC Critical Review of Environment Control, v.8, p.293-372, 1979.

SOUKUPOVÁ, J.; ROCK, B. N.; ALBRECHTOVÁ, J. Comparative study of two spruce species in a polluted mountainous region. New Phytologist, v.150, p.133-145, 2001.

TUCKER, S. C. The terminal idioblasts in Magnoliaceous leaves. American Journal of Botany, v.51, p.1051-1062, 1964.

TUFFI SANTOS, L. D. et al. Morphological responses of different eucalypt clones submitted to glyphosate drift.

Environmental and Experimental Botany, v.59, p.11-20, 2007.

VAUGHN, K.; DUKE, S. O. Function of polyphenol oxidase in higher plants. Physiologia Plantarum, v.60, p.106-112, 1984.

VOLLENWEIDER, P.; OTTIGER, M.; GÜNTHARDT-GOERG, M. S. Validation of leaf ozone symptoms in natural vegetation using microscopical methods. Environmental Pollution, v.124, p.101-118, 2003.

VOLLENWEIDER, P.; GÜNTHARDT-GOERG, M. S. Diagnosis of abiotic and biotic stress factors using the visible symptoms in foliage. Environmental Pollution, v.137, p.455-465, 2005. 
WEINSTEIN, L. H.; DAVISON, A. W. Native plant species suitable as bioindicators and biomonitors for airbone fluoride. Environmental

Pollution, v.125, p.3-11, 2003.
WEINSTEIN, L. H.; HANSEN, K. S. Relative susceptibilites of Brazilian vegetation to airborne fluoride. Pesquisa Agropecuária Brasileira, v.23, p.1125-1137, 1988. 
